\title{
Studies on Gastric Mucoproteins
}

\author{
THE ISOLATION AND CHARACTERIZATION OF THE MUCOPROTEIN OF THE \\ WATER-SOLUBLE MUCUS FROM PIG CARDIAC GASTRIC MUCOSA
}

\author{
By D. SNARY AND A. ALLEN \\ Department of Biochemistry, University of Newcastle upon Tyne, Newcastle upon Tyne NE1 7RU, U.K.
}

(Received 15 January 1971)

\begin{abstract}
1. Gel filtration of the water-soluble radioactive mucus produced three radioactive fractions, fraction A excluded on Sepharose 4B, fraction B included on Sepharose 4B but excluded on Sephadex G-200, and fraction C included on Sephadex G-200. 2. The specific radioactivities of fractions $A$ and $B$ were the same, with fraction $\mathrm{C} \mathrm{a}$ little lower, whether the material was labelled with ${ }^{14} \mathrm{C}$-labelled carbohydrate or with ${ }^{3} \mathrm{H}$-labelled protein prepared by incubation of mucosal scrapings in vitro with $\left[\mathrm{U}-{ }^{14} \mathrm{C}\right]$ glucose or $\left[\mathrm{G}-{ }^{3} \mathrm{H}\right]$ threonine respectively. 3. Fractions $\mathbf{A}$ and $\mathbf{B}$ had an analysis of protein $22 \%$, hexose $28 \%$, hexosamine $28 \%$, fucose $10 \%$ and sialic acid $1 \%$; fraction $\mathrm{C}$ had an analysis closely similar to this, except that it contained about $10 \%$ of a protein contaminant. 4 . All three fractions had closely similar A and $H$ blood-group activities. 5. Ultracentrifuge studies showed fractions A, B and C were polydisperse with $s_{25, \mathrm{w}}^{0}$ values of $18.7 \mathrm{~S}, 4.9 \mathrm{~S}$ and $3.9 \mathrm{~S}$ respectively. 6. The unfractionated water-soluble mucus contained only two peaks, fraction $\mathrm{A}$ 18.7S and a peak of $4.4 \mathrm{~S}$, which was a combination of fractions $B$ and $C$. 7. The radioactive mucoprotein accounted for $85 \%$ by weight of the soluble mucus and the results show that it consisted of two distinct fractions A and B-C, which were chemically, biosynthetically and immunologically very similar.
\end{abstract}

To understand the biological functions of gastric mucous secretions (Florey, 1962) it is necessary to isolate and characterize the molecular components of the secretions. The principal components of a number of gastrointestinal mucous secretions have been isolated and shown to be mucoproteins. Examples of such mucoproteins include ovine, bovine and porcine submaxillary mucoproteins (Gottschalk, 1966) and ovine colonic mucoprotein (Kent \& Marsden, 1963). With gastric mucus, the isolation of the macromolecular components is complicated by the complexity of gastric secretions (Glass, 1965). Among the mucosubstances isolated from gastric secretions are bloodgroup substances (Kabat, 1956), the intrinsic factor (Ellenbogen \& Highley, 1963), serum glycoproteins (Glass, Rich \& Stephenson, 1964), gastroferrin (Davis, Multani, Cepurneek \& Saltman, 1969), a sulphated mucoprotein (Pamer, Glass \& Horowitz, 1968) and sulphated mucopolysaccharides (Meyer, Smyth \& Palmer, 1937). These different mucosubstances from gastric secretions have been isolated either from gastric washouts or by enzymic digestion of the gastric mucosa. Studying gastric washouts has a number of associated problems, including swallowed saliva and refluxed duodenal contents
(Glass, 1965). Enzymic methods also have disadvantages and have been suggested to result in the digestion of the mucoproteins (Skoryna \& WaldronEdwards, 1967; Kristiansen \& Porath, 1968). The problems of the complexity of secretions and of enzymic digestion in vitro can be minimized by fractionating the water-soluble mucus from gastricmucosal scrapings from one region of the stomach. In a previous paper (Snary \& Allen, 1969) we reported the radioactive labelling of the mucoprotein secretions by pig gastric mucosal scrapings from the cardiac region, invitro. This paper describes the isolation by gel filtration and the characterization, without enzymic digestion in vitro, of these radioactive mucoproteins from pig cardiac mucosal scrapings.

\section{METHODS}

The preparation of mucosal scrapings from the cardiao region of pig stomach and the production in vitro of radioactive mucoprotein has been described (Snary, 1970). Neutral sugars and sialic acids were examined by the method of Allen \& Kent (1968). Cellulose acetate electrophoresis was carried out by the method of Smith (1960) and the strips were stained for carbohydrate by the periodic acid-Schiff's stain (Kohn \& Feinberg, 1965) and 
for protein by immersing the strips first in $10 \%(\mathrm{w} / \mathrm{v})$ trichloroacetic acid, drying, and then immersing the strips in $5 \%(w / v)$ solution of Coomassie Blue in water.

The following analytical methods were used: fucose (Gibbons, 1955); hexosamines (Ludoweig \& Benmaman, 1967); sialic acids (Aminoff, 1961), with $N$-acetylneuraminic acid as standard; uronic acids (Bitter \& Muir, 1962), with glucuronic acid as standard; and phosphate (Chen, Toribara \& Warner, 1956). Carbohydrate-positive material eluted from columns was determined by the anthrone method of Seifter, Dayton, Novic \& Muntwyler (1950). Quantitative values of hexose were determined by the orcinol method of Weimer \& Moshin (1953) with galactose as a standard. Values obtained for total hexose by the orcinol determination were corrected for interference by fucose, which gave $63 \%$ by weight of the $E_{540}$ value obtained with galactose. Sulphate was measured by the method of Pamer et al. (1968). Samples were first dialysed against $5 \%(\mathrm{w} / \mathrm{v}) \mathrm{MgCl}_{2}$ for $48 \mathrm{~h}$, followed by dialysis against six changes of water over $48 \mathrm{~h}$. The samples were then freeze-dried and hydrolysed by incubating with $2 \mathrm{ml}$ of $5 \mathrm{M}$-formic acid for $18 \mathrm{~h}$ at $105^{\circ} \mathrm{C}$. The hydrolysates were incubated for $1 \mathrm{~h}$ with $5 \mathrm{ml}$ of a $0.1 \%$ solution of benzidine in ethanol at room temperature, centrifuged at $2000 \mathrm{~g}$ for $10 \mathrm{~min}$ and the supernatants decanted. The residue was suspended in ethanol, centrifuged, resuspended in $5 \mathrm{ml}$ of $1 \mathrm{M}-\mathrm{HCl}$ and centrifuged at $2000 \mathrm{~g}$ for $10 \mathrm{~min}$, and the $E_{248}$ of the supernatant was measured.

Amino acid analyses were performed by the method of Mahowald, Noltmann \& Kuby (1962) by using a Locarte amino acid analyser. Samples were hydrolysed for 10,18 , 30,40 and $70 \mathrm{~h}$ and the correction factors were estimated for the decay of serine and threonine, and for the slow appearance of leucine and valine.

Blood-group-active substances were prepared from mucosal scrapings by pepsin digestion (Kabat, 1956) and phenol purification (Morgan \& King, 1943). The bloodgroup activity was measured as the amount of material $(\mu \mathrm{g} / 0.1 \mathrm{ml})$ that would just inhibit the complete agglutination of erythrocytes by a dilution of antiserum such that in the absence of the blood-group-active substance the antiserum just gave complete agglutination of the erythrocytes (Kabat \& Bezer, 1945). Human anti-A and an anti-H preparation from Ulex europeus were the antisera used.

The water-soluble fraction $(5 \mathrm{ml}$ of $3 \mathrm{mg} / \mathrm{ml})$ was fractionated on a Sepharose $4 B$ column $(85 \mathrm{~cm} \times 2.5 \mathrm{~cm})$ eluted with $0.2 \mathrm{M}-\mathrm{NaCl}$ by upward flow. The material eluted in the total volume of the Sephadex 4B column was concentrated to $5 \mathrm{ml}$ by vacuum dialysis $(30 \mathrm{mmHg}$ pressure), applied to a Sephadex G-200 column $(85 \mathrm{~cm} \times$ $2.5 \mathrm{~cm}$ ) and eluted with $0.2 \mathrm{M}-\mathrm{NaCl}$ by upward flow. The fractions obtained by gel filtration were dialysed against six changes of water for $48 \mathrm{~h}$ and freeze-dried. The Sephadex G-100 column $(25 \mathrm{~cm} \times 1.5 \mathrm{~cm})$ was eluted with water by downward flow; $2 \mathrm{ml}$ samples ( $5 \mathrm{mg}$ dry wt.) were loaded on to the column.

Sedimentation-velocity studies were performed on solutions which had been dialysed for $48 \mathrm{~h}$ against buffer: $0.18 \mathrm{M}-\mathrm{KCl}-0.02 \mathrm{M}$-potassium acetate adjusted to $\mathrm{pH} 5.5$ with acetic acid, $0.02 \% \mathrm{NaN}_{3}\left(\eta_{\text {rel.,25 }}=1.017, \rho_{25}=\right.$ $1.011 \mathrm{~g} / \mathrm{ml}$ ). The samples were clarified by centrifuging at $2000 \mathrm{~g}$ for $15 \mathrm{~min}$ before sedimentation studies. Sedimentation-velocity runs were performed at $25^{\circ} \mathrm{C}$ with a Beckman model $\mathbf{E}$ analytical ultracentrifuge. Sedimentation coefficients were calculated from radial displacement of the maximum refraction gradient and were corrected for buffer viscosity and density. Linear relations were obtained when values of $1 / 8$ were plotted against mean plateau concentrations. The latter were obtained from Schlieren peak areas which, together with areas used for calculating optical recovery in sedimentation runs, were corrected for radial dilution. These values were also used for calculating the concentration-dependent coefficients $K$ from:

$$
K=s^{0} \cdot \mathrm{d}(1 / s) / \mathrm{d} c \quad \text { (Creeth \& Knight, 1967). }
$$

\section{RESULTS}

Fractionation of the water-soluble material from the non-diffusible fraction. The water-soluble material, labelled with ${ }^{14} \mathrm{C}$-labelled carbohydrate, from incubation of the cardiac-mucosal scrapings with

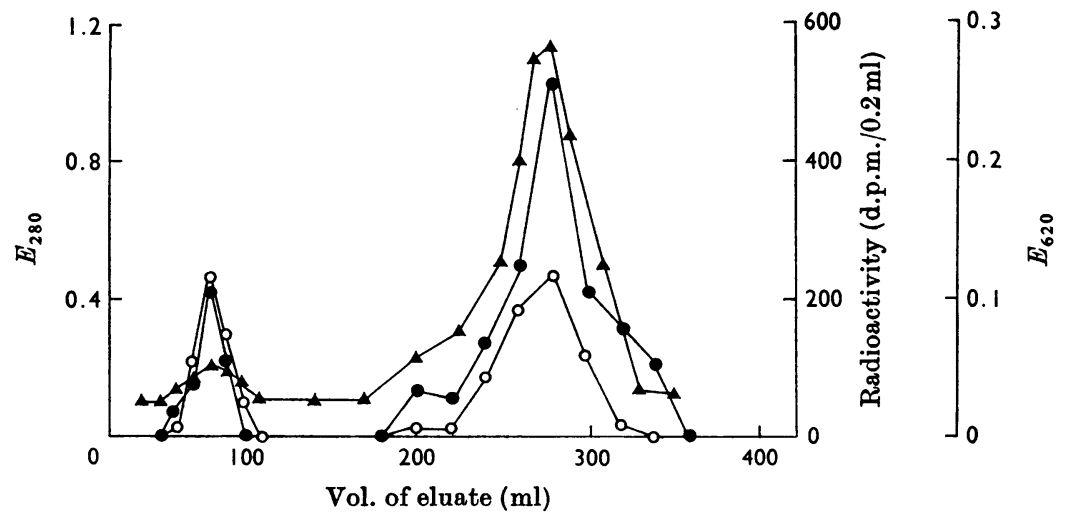

Fig. 1. Fractionation on a column $(85 \mathrm{~cm} \times 2.5 \mathrm{~cm})$ of Sepharose $4 B$ of the water-soluble fraction radioactively labelled from $\mathrm{D}-\left[\mathrm{U}-{ }^{14} \mathrm{C}\right]$ glucose. The sample $(5 \mathrm{ml}$ of $3 \mathrm{mg} / \mathrm{ml})$ was eluted by upward flow with $0.2 \mathrm{M}-\mathrm{NaCl}$. $\Delta$, Radioactivity; $\bullet, E_{280}$; O, anthrone-positive material ( $\left.E_{620}\right)$. 


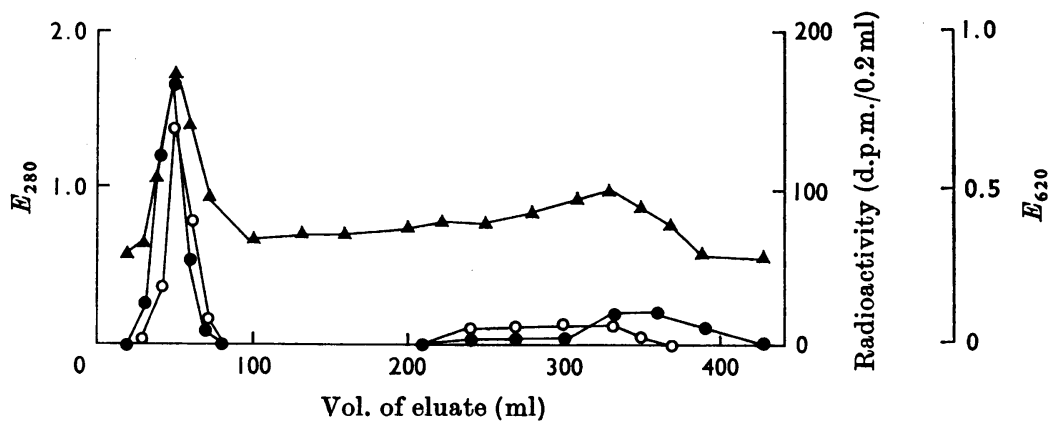

Fig. 2. Fractionation on Sephadex G-200 of fraction B-C radioactively labelled from $D-\left[U-{ }^{14} \mathrm{C}\right] \mathrm{glucose}$. The second peak eluted from Sepharose 4B (Fig. $1 ; 160 \mathrm{ml}$ ) was concentrated to $5 \mathrm{ml}$, loaded on to the column $(85 \mathrm{~cm} \times 2.5 \mathrm{~cm})$ and eluted by upward flow with $0.2 \mathrm{M}-\mathrm{NaCl}$. $\Delta$, Radioactivity; $\bullet, E_{280}$; O, anthronepositive material $\left(E_{620}\right)$.

Table 1. Fractions obtained from the non-diffusible material radioactively labelled from $\mathrm{D}-\left[\mathrm{U}-{ }^{14} \mathrm{C}\right]$ glucose and $\mathrm{DL}-\left[\mathrm{G}-{ }^{3} \mathrm{H}\right]$ threonine

The radioactive scrapings were dialysed against water for 3 days and centrifuged at $5000 \mathrm{~g}$ for $20 \mathrm{~min}$ to separate the water-soluble and water-insoluble fractions. The results are average values from two experiments; numbers in parentheses represent the range of values given.

\begin{tabular}{|c|c|c|c|c|c|}
\hline \multirow[b]{2}{*}{ Fraction } & \multirow{2}{*}{$\begin{array}{l}\text { Amount isolated } \\
\text { (mg/g of mucosal } \\
\text { scrapings) }\end{array}$} & \multirow{2}{*}{$\begin{array}{l}\text { Percentage recovery } \\
\text { from water-soluble } \\
\text { fraction by weight }\end{array}$} & \multicolumn{2}{|c|}{$\begin{array}{l}\text { Specific radioactivity } \\
\text { (d.p.m./mg dry wt.) }\end{array}$} & \multirow[b]{2}{*}{${ }^{3} \mathrm{H} /{ }^{14} \mathrm{C}$ Ratio } \\
\hline & & & ${ }^{3} \mathrm{H}$ & ${ }^{14} \mathrm{C}$ & \\
\hline $\begin{array}{l}\text { Water-insoluble } \\
\text { fraction }\end{array}$ & 918 & 一 & $41500( \pm 2000)$ & $4650( \pm 200)$ & 8.9 \\
\hline $\begin{array}{l}\text { Water-soluble } \\
\text { fraction }\end{array}$ & 82 & 100 & $90800( \pm 4000)$ & $9010( \pm 500)$ & 10.1 \\
\hline Fraction A & 17.4 & 20 & $103000( \pm 15000)$ & $10500( \pm 1900)$ & 9.8 \\
\hline Fraction B & 29.5 & 36 & $119000( \pm 20000)$ & $11350( \pm 2900)$ & 10.5 \\
\hline Fraction $\mathbf{C}$ & 34.5 & 42 & $80500( \pm 5000)$ & $8300( \pm 1000)$ & 9.7 \\
\hline
\end{tabular}

$\left[\mathrm{U} \cdot{ }^{14} \mathrm{C}\right]$ glucose was fractionated by gel filtration. Three distinct peaks were obtained with coincident profiles of radioactivity, anthrone-positive material and $E_{280}$ for each column run (Figs. 1 and 2). On Sepharose 4B two fractions were obtained; fraction $A$ in the excluded volume and fraction $B-C$ in the included volume. On Sephadex G-200 fraction B-C gave a further two fractions, fraction $B$ in the excluded volume and fraction $\mathrm{C}$ a disperse fraction in the included volume. All the anthrone-positive material in fraction $\mathrm{C}$ was excluded from Sephadex G-100 but some (about 20\%) of the $280 \mathrm{~nm}$-absorbing material was found in the included volume. With all fractionations by gel filtration over $95 \%$ of the freeze-dried weight and over $90 \%$ of the radioactivity originally applied to the columns was recovered.

Non-radioactive fractions A and B were prepared by the above methods of gel filtration, dialysed
Table 2. Chemical analyses of fractions $A, B$ and $C$

The analytical methods used were: fucose (Gibbons, 1955); hexose (Weimer \& Moshin, 1953); hexosamines (Ludoweig \& Benmaman, 1967); sialic acids (Aminoff, 1961); and protein from the amino acid analyses (Mahowald et al. 1962). The material was not corrected for moisture and ash content. The results are average values from four experiments; numbers in parentheses represent the range of values given.

$\%$ by weight of freeze-dried material

Fraction A Fraction B Fraction C

$\begin{array}{lrrr}\text { Hexose } & 28.0( \pm 1.5) & 28.5( \pm 2.0) & 28.0( \pm 3.0) \\ \text { Hexosamine } & 29.6( \pm 2.5) & 28.4( \pm 1.0) & 24.4( \pm 3.6) \\ \text { Fucose } & 11.3( \pm 0.3) & 8.8( \pm 0.7) & 8.4( \pm 0.9) \\ \text { Sialic acid } & 0.9( \pm 0.3) & 0.9( \pm 0.2) & 0.5( \pm 0.1) \\ \text { Protein } & 21.7( \pm 0.7) & 21.8( \pm 1.1) & 30.6( \pm 4.6)\end{array}$


against water and rechromatographed on Sepharose 4B. Fraction A isolated by gel filtration, apparently free from fraction $\mathrm{B}-\mathrm{C}$, when rechromatographed on Sepharose 4B showed the presence of $20 \%$ of anthrone-positive material where fraction $\mathrm{B}-\mathrm{C}$ would have been eluted. Similarly fraction B-C, isolated free from fraction $A$, when rechromatographed on Sepharose $4 B$ was found to contain $15 \%$ of anthronepositive material where fraction A eluted.

Fractions $\mathrm{A}, \mathrm{B}$ and $\mathrm{C}$ and the total water-soluble fraction all gave the same pattern on cellulose acetate electrophoresis in borate buffer, pH9.5. Two bands were produced, both staining for protein and carbohydrate, one a dense band at the origin and the other a diffuse band $20 \mathrm{~mm}$ wide with its staining maximum $19 \mathrm{~mm}$ from the origin in the direction of the anode.

Analysis of isolated fractions $A, B$ and $C$. The amounts by weight and the specific radioactivities of the freeze-dried fractions from gel filtration of radioactively labelled water-soluble material are shown in Table 1. The specific radioactivities of the ${ }^{14} \mathrm{C}$-labelled carbohydrate and the ${ }^{3} \mathrm{H}$-labelled protein for fractions $A$ and $B$ are the same within the limits of the experiment and those of fraction $\mathrm{C}$ are somewhat lower. The ${ }^{14} \mathrm{C} /{ }^{3} \mathrm{H}$ ratio for fraction $\mathrm{C}$, for the water-soluble and water-insoluble fractions, is the same as for fractions A and B.

Acid hydrolysis and chromatography of the unfractionated water-soluble material showed galactose and fucose to be the sole neutral sugar constituents apart from traces of glucose and mannose. Similarly the unfractionated water-soluble material was shown to contain galactosamine, glucosamine and both $N$-acetyl- and $N$-glycollyl-neuraminic acid. The chemical analyses of fractions A, B and $\mathrm{C}$ are shown in Table 2. The analysis accounted for between $88 \%$ and $92 \%$ of the freeze-dried material. Allowing for variations from sample to sample, the overall analyses of $A$ and $B$ are the same. The analysis for fraction $C$ was more variable but was similar to fractions A and B, except for a higher protein content. Maximum release of sialic acids from the water-soluble fraction, as measured by the thiobarbituric acid reaction, was obtained after $40 \mathrm{~min}$ hydrolysis at $80^{\circ} \mathrm{C}$ with $0.05 \mathrm{M}$-sulphuric acid. However, $84 \%$ of the bound sialic acid was released from the macromolecular material by the conditions of the thiobarbituric acid assay alone without prior acid hydrolysis. Table 3 shows that the amino acid contents of fractions $A$ and $B$ are the same but that fraction $\mathrm{C}$ has a different amino acid composition as well as a higher percent. age of amino acids. The amino acids threonine, serine and proline represent $31 \%$, and aspartic acid and glutamic acid $18 \%$, of the total amino acids found in fractions A and B. Analyses for sulphate, phosphate and uronic acids showed that each constituted $0.2 \%$ or less of the total watersoluble material.

Blood-group substance activity. Fractions A and B possess $A$ and $H$ blood-group activity, the activities for the two fractions being within the limits of the assay, of the same order of magnitude (Table 4). A lower blood-group A activity was found for fraction $C$ and at a concentration of $30 \mu \mathrm{g} / 0.1 \mathrm{ml}$ this

Table 3. Amino acid composition of fractions from the mucosal scrapings from the cardiac region of pig stomach

The results are average values from two experiments. The blood-group substance was prepared by pepsin digestion (Kabat, 1956) and phenol extraction (Morgan \& King, 1943) of mucosal scrapings.

Water-soluble fractions ( $\mu \mathrm{mol} / \mathrm{mg}$ of dry wt. of material)

$$
\begin{aligned}
& \text { Asp } \\
& \text { Thr } \\
& \text { Ser } \\
& \text { Glu } \\
& \text { Pro } \\
& \text { Gly } \\
& \text { Ala } \\
& \text { Val } \\
& \text { Met } \\
& \text { Ile } \\
& \text { Leu } \\
& \text { Tyr } \\
& \text { Phe } \\
& \text { His } \\
& \text { Lys } \\
& \text { Arg }
\end{aligned}
$$

\begin{tabular}{ccc}
\multicolumn{3}{c}{$\begin{array}{c}\text { Water-soluble fractions } \\
(\mu \mathrm{mol} / \mathrm{mg} \text { of dry wt. of material) }\end{array}$} \\
\hline A & B & C \\
0.128 & 0.132 & 0.249 \\
0.162 & 0.174 & 0.141 \\
0.152 & 0.175 & 0.188 \\
0.158 & 0.155 & 0.274 \\
0.114 & 0.120 & 0.136 \\
0.159 & 0.150 & 0.260 \\
0.157 & 0.168 & 0.289 \\
0.109 & 0.119 & 0.159 \\
0.018 & 0.020 & 0.042 \\
0.063 & 0.070 & 0.086 \\
0.098 & 0.098 & 0.167 \\
0.036 & 0.047 & 0.053 \\
0.041 & 0.041 & 0.068 \\
0.025 & 0.030 & 0.025 \\
0.063 & 0.069 & 0.181 \\
0.067 & 0.067 & 0.076
\end{tabular}

Blood-group
substance preparation
0.044
0.225
0.173
0.062
0.182
0.067
0.082
0.073
0.005
0.023
0.046
0.007
0.013
0.023
0.021
0.037




\section{Table 4. Blood-group activity of the water-soluble fractions and of a blood-group preparation from pig stomach}

The pig stomach blood-group substance was prepared by pepsin digestion (Kabat, 1956) and phenol extraction (Morgan \& King, 1943) of mucosal scrapings. The blood-group activity was measured as the amount of material $(\mu \mathrm{g} / 0.1 \mathrm{ml})$ that would inhibit the complete agglutination of erythrocytes by a dilution of antiserum such that in the absence of the blood-group-active substance the antiserum just gave complete agglutination of the erythrocytes.

Water-soluble fraction
Fraction A
Fraction B
Fraction C
Pig stomach blood-group substance
Ovarian-cyst blood-group substance A
Ovarian-cyst blood-group substance H

Blood-group A activity

$\begin{array}{cc}1.6 & 3.0 \\ 0.7 & 0.7 \\ 1.5 & 1.5 \\ 7.2 & >30 \\ 0.2 & 0.4 \\ 0.2 & >50 \\ >50 & 0.4\end{array}$

fraction had no detectable blood-group $\mathbf{H}$ activity. The blood-group activities of fractions $A$ and $B$ were similar to those of purified blood-group substances prepared from ovarian cysts and from pepsin digestion of pig stomach.

For comparison with fractions $\mathbf{A}$ and $\mathbf{B}$, pig gastric blood-group material was prepared by pepsin digestion and phenol extraction of dialysed mucosal scrapings containing ${ }^{14} \mathrm{C}$-labelled carbohydrate from $\left[\mathrm{U}-{ }^{14} \mathrm{C}\right] \mathrm{glucose}$. The distribution of radioactivity arising from the pepsin digestion and phenol purification procedures is shown in Scheme 1. The purified blood-group material had both blood-group $A$ and $H$ activities comparable with those of bloodgroup material from ovarian cysts (Table 4), and contained $4.4 \%$ of the radioactivity in the starting material. The amino acids serine, threonine and proline accounted for $54 \%$ of the total amino acids in the blood-group substance, and aspartic acid and glutamic acid accounted for only $10 \%$ (Table 3).

Sedimentation analysis. The average sedimentation coefficients of fractions $A, B$ and $C$ were all concentration dependent and linear plots of $1 / s$ against concentration were extrapolated to zero concentration to give $s^{0}$ values (Fig. 3). Fractions $\mathrm{B}$ and $\mathbf{C}$ gave single broad peaks, indicating polydispersity, with $s_{25, w}^{0}$ values of $4.9 \mathrm{~S}$ and $3.9 \mathrm{~S}$ respectively. Fraction A exhibited two peaks, the major faster-sedimenting peak having an $s_{25 \text {,w }}^{0}$ value of $18.7 \mathrm{~S}$. This peak showed marked boundary sharpening at concentrations above $2 \mathrm{mg} / \mathrm{ml}$. The minor peak in fraction $A$ represented approx. $20 \%$ of the total sedimenting material and was polydisperse. The low solubility of fraction A meant that this minor component was not present at sufficiently high concentrations for an extrapolated $s_{25 \text {,w value }}^{0}$ to be measured. However, for two concentrations the area under the peak of the minor component was measurable and the respective sedimentation coefficients lay on a straight line plot of $1 / s$ against area under the peak for fraction B (Fig. 3). It was found that material was lost from solution during the sedimentation-velocity runs and the optical recoveries of the peaks in fractions $A, B$ and $\mathrm{C}$, corrected for radial dilution, were $80 \%, 85 \%$ and $85 \%$ respectively. The concentration of samples used was calculated from the area under the peak at the mid-point of the run. For the peaks in fractions $\mathrm{B}$ and $\mathrm{C}$ these values were both $90 \%$ of the initial concentration. The presence of the minor peak in fraction $A$, together with the loss of material during sedimentation, means that the area under the main peak represented only $65 \%$ of the initial material. The concentration-dependence coefficient $K$ (Table 5) for the major 18.7S peak for fraction $A$, and the peaks of fractions $B$ and $C$ were obtained by multiplying the value of $s_{25, w}^{0}$ by the slope $\mathrm{d}(1 / s) / \mathrm{d} c$ (Fig. 3) (Creeth \& Knight, 1967).

Sedimentation analysis of the unfractionated water-soluble fraction showed the presence of two major peaks. Both peaks were polydisperse and their sedimentation velocities were concentrationdependent. At higher concentrations, above $2 \mathrm{mg} / \mathrm{ml}$, the faster-moving peak showed marked boundary sharpening and at concentrations of $8 \mathrm{mg} / \mathrm{ml}$ or above the total material sedimented as a single hypersharp boundary. The $s_{25}^{0}$,w value for the faster-moving peak seen at concentrations below $8 \mathrm{mg} / \mathrm{ml}$ was $18.7 \mathrm{~S}$, the same as the value obtained for the major peak in fraction $A$. The $s_{25, w}^{0}$ value for the slower-moving peak was $4.4 \mathrm{~S}$ which was midway between the values of $4.9 \mathrm{~S}$ and $3.9 \mathrm{~S}$ found for the peaks in fractions $B$ and $C$ respectively (Table 4) and the same as the average sedimentation coefficient for fraction B-C. This peak in fraction B-C was concentration-dependent with a $K$ value of $0.11 \mathrm{ml} / \mathrm{mg}$.

To eliminate the possible effects of freeze-drying, the total water-soluble fraction, which had not been freeze-dried but concentrated by dialysis under vacuum (30 mmHg pressure), was analysed by sedimentation velocity. This material gave the 


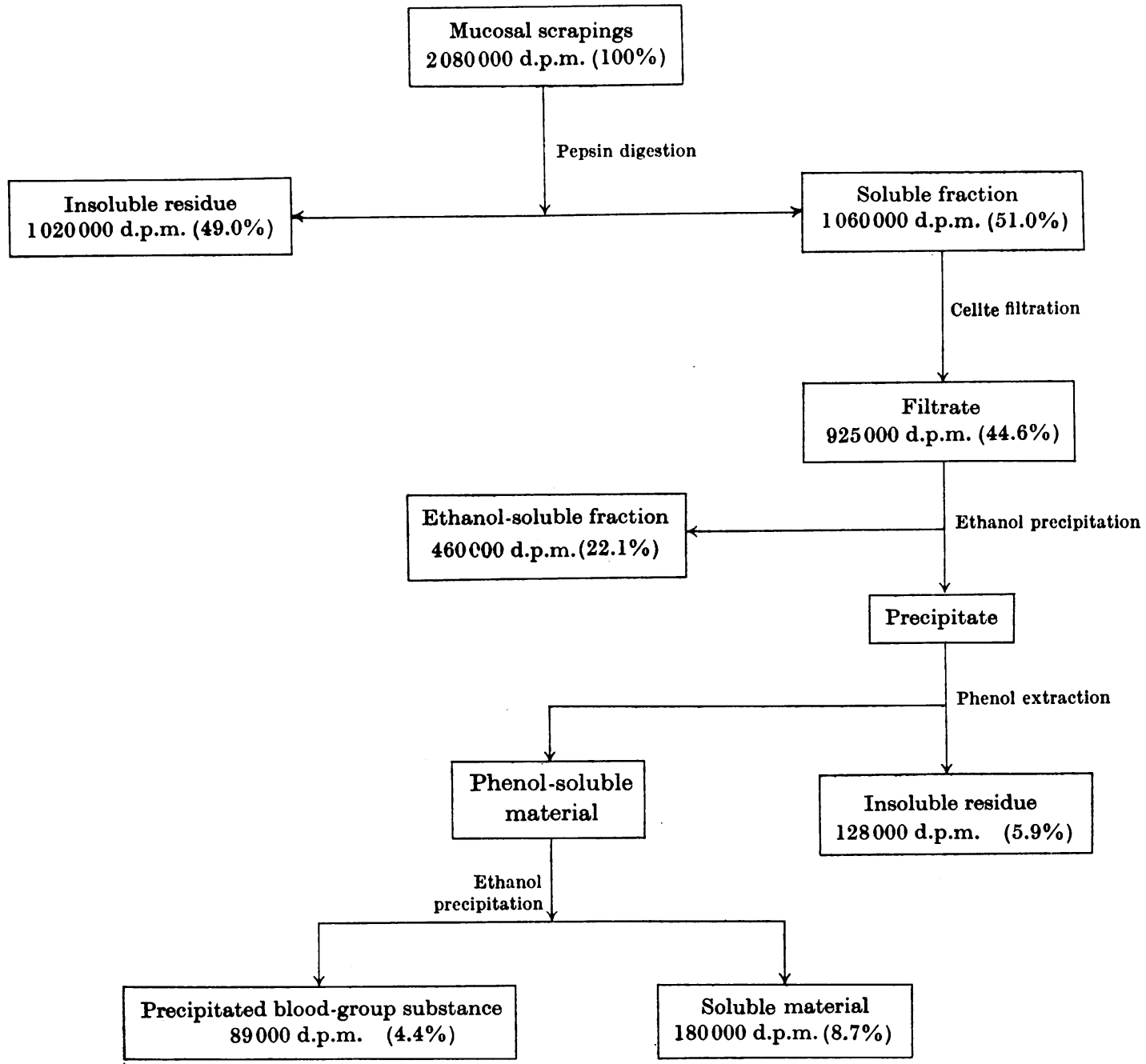

Scheme 1. Preparation of blood-group-active material from mucosal scrapings radioactively labelled from $\left[\mathrm{U}^{14} \mathrm{C}\right]$ glucose. Pepsin digestion, Celite filtration, and ethanol precipitation were by the method of Kabat (1956) and phenol purification by the method of Morgan \& King (1943).

same sedimentation pattern as the water-soluble material which had been freeze-dried, with two peaks of $8_{25, w}^{0}$ values of $18.7 \mathrm{~S}$ and $4.4 \mathrm{~S}$.

\section{DISCUSSION}

Gel filtration of the water-soluble material from mucosal scrapings of the cardiac region of pig stomach gave three fractions, A, B and C. Each fraction contained radioactivity from [U. $\left.{ }^{14} \mathrm{C}\right] \mathrm{glu}$ cose and $\left[\mathrm{G}-{ }^{3} \mathrm{H}\right]$ threonine incorporated solely into the carbohydrate and protein respectively of the mucoprotein (Snary \& Allen, 1971). These three mucoprotein fractions were shown to be chemically and biosynthetically very closely related to each other, although fraction $\mathrm{C}$ appeared to contain various amounts of protein contamination. This conclusion is based on the following results: the specific radioactivities of fractions $A$ and $B$ were the same (with that of fraction $C$ lower) whether the mucoprotein was radioactively labelled with ${ }^{14} \mathrm{C}$. labelled carbohydrate or with ${ }^{3} \mathrm{H}$-labelled protein (Table 1). Further, the ratio of ${ }^{3} \mathrm{H}$-labelled protein to ${ }^{14} \mathrm{C}$-labelled carbohydrate was the same for fractions $A, B$ and $C$ as well as for the water-soluble and water-insoluble fractions from the gastrio 
mucosa. The blood-group activities of fractions $A$ and $B$ were closely similar, that of fraction $\mathbf{C}$ being lower (Table 4). The chemical analyses, within the limits of experimental error, were identical for fractions $A$ and $B$, whereas fraction $C$ had a higher protein content. Fraction $\mathrm{C}$, fractionated further on Sephadex G-100, gave only one peak containing carbohydrate in the excluded volume but showed the presence of other material in the included volume of the column, possibly the contaminant protein, absorbing light at $280 \mathrm{~nm}$. Cellulose acetate electrophoresis of all three fractions gave the same pattern, that is one diffuse band moving the same distance towards the anode and a densely staining band at the origin, both bands staining for carbohydrate and protein.

The chemical analyses of fractions A and B were those of a mucoprotein composed of hexose (identi-

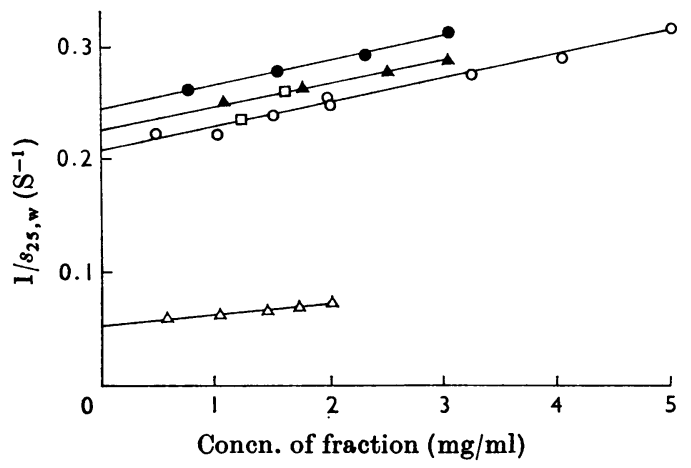

Fig. 3. Concentration dependence of sedimentation coefficients of fractions obtained from the water-soluble fraction by gel filtration. $\Delta$, The major component in fraction $A ; O$, fraction $B$; $\bullet$, fraction $C ; \Delta$, fraction $B-C$; $\square$, the minor peak in fraction $A$. The solvent used was $0.18 \mathrm{~m}-\mathrm{KCl}-20 \mathrm{~mm}$-potassium acetate buffer, pH 5.5. Concentrations were calculated from the area under the peaks of refractive index gradient at the mid-point of sedimentation. fied chromatographically as galactose) $28 \%$, hexosamine $29 \%$, fucose $10 \%$, sialic acid $1 \%$ and protein $22 \%$. With fraction $\mathrm{C}$ the protein content was higher $(35 \%)$ with a corresponding decrease in the carbohydrate content. The composition of the pig gastric mucin is thus similar to those found for other mucoproteins, for example blood-group substances from pig stomach (Kabat, 1956), ovarian-cyst bloodgroup substances (Watkins, 1966) and bovine cervical mucoprotein (Gibbons \& Roberts, 1963). A low sialic acid content was found ( $1 \%)$, unlike ovine submaxillary mucoprotein (24\%; Gottschalk, 1966) and ovine colonic mucoprotein (14\%; Allen, 1966). During the thiobarbituric acid assay without acid hydrolysis (Gibbons, 1963) $84 \%$ of the sialic acid was released and it is quite possible that such labile sialic acid residues would be susceptible to the acidity of the stomach contents, especially if $\mathrm{pH}$ values of 1.0 that have been recorded in the stomach (Marcussen, 1970) are of general occurrence. No sulphate was found in the mucoprotein from pig stomach mucosa, unlike mucoproteins from ovine colonic mucosa (Kent \& Marsden, 1963) or dog stomach mucosa (Pamer et al. 1968). Low concentrations of phosphate and sulphate, and the absence of uronic acids in the total water-soluble material, rule out the presence of nucleic acids or acid mucopolysaccharides in this preparation, although Meyer et al. (1937) have found sulphated mucopolysaccharides in the pepsin-digestion products of pig gastric mucosa.

Chemical analyses together with the immunological results suggest that fractions $A, B$ and $C$ are a less degraded form of the blood-group substances isolated from pig stomach mucosa. Isolated fractions $A$ and $B$ were blood-group $A$ and blood-group $H$ active, although only blood-group $A$ activity could be detected in fraction C. Moreover the bloodgroup $A$ and blood-group $\mathbf{H}$ activities in fractions $A$ and $B$ were of a similar order of magnitude to those found for purified blood-group substances from ovarian cysts and pig stomach. The blood-group

Table 5. Physical properties of fractions $A, B$ and $C$

For experimental details see the Methods section.

\begin{tabular}{lccc}
\multicolumn{1}{c}{} & & Molecular weight* \\
Fraction & $s_{25, \mathrm{w}}^{0}$ & $K(\mathrm{ml} / \mathrm{mg})$ & $\left(M_{\text {s,D }}\right)$ \\
A & 18.7 & 0.26 & $1.85 \times 10^{6}$ \\
B & 4.9 & 0.12 & $1.1 \times 10^{5}$ \\
C & 3.9 & 0.09 & - \\
B-C & 4.4 & 0.11 & - \\
Water-soluble fraction & 18.7 & - & - \\
& 4.4 & - & - \\
& & &
\end{tabular}


preparation from pig stomach had less protein (15\%) than fractions A and B (22\%). Further, fractions A and $B$ had a lower content of serine, threonine and proline ( $35 \%$ of the total amino acids) and a higher aspartic acid and glutamic acid content $(18 \%)$ than the pig gastric blood-group substance $(56 \%$ serine, threonine, and proline and $10 \%$ aspartic acid and glutamic acid). The amino acid composition found for the pig blood-group substance was similar to that found by Pusztai \& Morgan (1963).

Preparation of blood-group substance by pepsin digestion and phenol extraction of gastric mucosa labelled with radioactivity from $\left[\mathrm{U}-{ }^{14} \mathrm{C}\right]$ glucose showed that the purified blood-group substance accounted for only $4 \%$ of the original radioactive mucoprotein. Since all the radioactivity in the water-soluble material is in blood-group-active material and the radioactivity in the water-insoluble fraction is in a similar blood-group-active mucoprotein (Snary, 1970), these results show that only a small percentage of the total blood-group-active material is isolated from gastric mucosa by the standard method of pepsin digestion and phenol purification.

Examination of the unfractionated water-soluble material by sedimentation velocity showed the presence of two peaks, whereas three fractions were obtained by gel filtration. The slowest sedimenting peak of the water-soluble fraction had $s_{25, w}^{0} 4.4 \mathrm{~S}$, which was midway between the $s_{25 \text {, w }}^{0}$ values found for fractions $B(4.9 S)$ and $C(3.9 S)$. Further, the $K$ value for the slope of $1 / s$ against concentration plot for the $4.4 \mathrm{~S}$ peak was $0.11 \mathrm{ml} / \mathrm{mg}$, midway between the $K$ values for fraction $B(0.12 \mathrm{ml} / \mathrm{mg})$ and fraction $\mathrm{C}(0.09 \mathrm{ml} / \mathrm{mg})$. Examination of fraction $\mathrm{B}-\mathrm{C}$ by gel filtration on Sephadex G-200 showed no distinct separation of radioactivity between fraction $B$ and the included fraction C (Fig. 2). Thus it would seem likely from these results and the constant ratio of specific activities with ${ }^{14} \mathrm{C}$-labelled carbohydrate and ${ }^{3} \mathrm{H}$-labelled protein (Table 1 ) that fractions $\mathrm{B}$ and $\mathrm{C}$ are fractions of the same polydisperse mucoprotein component, and this polydispersity is sufficient to cause the material to spread through the excluded and included volumes of Sephadex G-200.

Fraction A examined by sedimentation velocity contained two peaks, the major faster-sedimenting peak having $s_{25, \mathrm{w}}^{0} 18.7 \mathrm{~S}$, the same as the fastersedimenting peak present in the water-soluble fraction. The second peak present in fraction $A$ comprised approx. $20 \%$ of the material and was found to be similar in physical behaviour to fraction B. The area under the minor peak was found to lie on the line of $1 / s$ against area under the peak plot for fraction B (Fig. 4). Further, the $s_{25, w}^{0}$ value for this minor peak was found to be $3.5 \mathrm{~S}$ in $0.2 \mathrm{M}$ potassium chloride buffer, $\mathrm{pH} 8.5$, containing $0.2 \mathrm{M}$-2-mercaptoethanol, the same value being given by fraction $\mathbf{B}$ under these conditions (Snary et al. 1970).

Since fractions A and B are chemically and biosynthetically identical, this suggests that fraction A may be a polymer of fraction B-C. Since no evidence from sedimentation-velocity or gel-filtration studies for material of a molecular size between the two fractions was obtained this must be a distinct polymerization with no intermediate forms. The presence of material similar to fraction B-C in fraction A shown by gel-filtration and sedimentation-velocity analysis is compatible with this postulate. Further, examination of fraction B by gel filtration on Sepharose $4 \mathrm{~B}$ showed the presence of material in the excluded volume where fraction A would have separated. However, sedimentationvelocity analysis of fraction $B$ did not show the presence of any peak analogous to the major peak in fraction $A$, although this may have been because this peak was at too low a concentration to be detected by sedimentation-velocity analysis. Alternatively, there may not be fraction A-like material present in fraction $B$ and the material present in the excluded volume of Sepharose 4B on gel filtration of fraction $B$ may be due to non-specific aggregates of fraction B material sufficiently large to appear in the excluded volume on Sepharose 4B. This material would thus be present in fraction $A$ and might account for the presence of fraction $B$ material in fraction $A$ by disaggregating in subsequent experimental procedures. Thus the appearance of fraction A material in fraction $\mathrm{B}-\mathrm{C}$, and vice versa, does not necessarily mean that the two fractions are interconvertible. It is also possible that fraction B-C may be an enzymic digestion product of fraction A or that both fraction $A$ and fraction $B-C$ may be enzymic degradation products of a larger mucoprotein molecule present in the water-insoluble mucus.

Studies in vivo have shown that the surface mucosal cells of the stomach secrete the mucous lining (Ito, $1965)$ and that this mucous lining contains bloodgroup-active mucoproteins (Szulman, 1960). We have shown that surface mucosal scrapings from the cardiac region of pig stomach incorporated radioactivity in vitro from $\left[\mathrm{U}-{ }^{14} \mathrm{C}\right]$ glucose, $\left[\mathrm{G}-{ }^{3} \mathrm{H}\right]$ threonine or $\left[\mathrm{G}-{ }^{3} \mathrm{H}\right]$ serine into the carbohydrate and protein respectively of a single type of mucoprotein which possesses blood-group activity. This mucoprotein comprises the majority of the water-soluble mucus, since $84 \%$ by weight of the total material was radioactive mucoprotein calculated from the specific radioactivity of the fraction $\mathrm{C}$ compared with that of fractions A and B. Further, the viscosity of the isolated mucoprotein fractions in $0.2 \mathrm{M}-\mathrm{KCl}$ buffer, $\mathrm{pH} 5.5$, is sufficient to account for the viscosity of the water-soluble mucus (Snary et al. 1970). Radioactive-labelling experiments with 
Pronase digestion and with solvent extractions show that this mucoprotein is also the principal mucin in the highly viscous water-insoluble material (Snary, 1970). It is therefore reasonable to state that this mucoprotein is the principal mucin secretion of the surface epithelial cells of the cardiac region of the pig stomach. The detailed structure of this mucoprotein is still unknown, although both fractions A and B have been shown to consist of subunits which can be dissociated with mercaptoethanol (Snary et al. 1970). Superimposed on this is the undefined relationship of fraction $A$ and fraction B-C, which although biosynthetically and chemically very similar, with distinct molecular-weight distributions, are as yet not interconvertible. It is likely that the state of the mucus in vivo depends on interactions between the soluble mucoprotein fractions $\mathrm{A}$ and $\mathrm{B}-\mathrm{C}$ described here.

We thank Dr R. H. Pain for helpful discussions and other members of the Department of Biochemistry, Newcastle upon Tyne, for their help. We also thank Professor W. M. Watkins for a gift of ovarian-cyst bloodgroup substance. The authors are also grateful to the Science Research Council for a Scholarship for Training in Research to D.S. and to the Medical Research Council for the continued support of this work.

\section{REFERENCES}

Allen, A. (1966). D.Phil. Thesis: University of Oxford. Allen, A. \& Kent, P. W. (1968). Biochem. J. 106, 301. Aminoff, D. (1961). Biochem. J. 81, 384.

Bitter, T. \& Muir, H. M. (1962). Analyt. Biochem. 4, 330. Chen, P. S., Toribara, T. Y. \& Warner, H. (1956). Analyt. Chem. 28, 1756.

Creeth, J. M. \& Knight, C. G. (1967). Biochem. J. 105, 1135.

Davis, P. S., Multani, J. S., Cepurneek, C. P. \& Saltman, P. (1969). Biochem. biophys. Res. Commun. 37, 532.

Ellenbogen, L. \& Highley, D. R. (1963). Vitams Horm. 21, 1 .

Florey, H. W. (1962). Gastroenterology, 43, 326.

Gibbons, M. N. (1955). Analyst, Lond., 80, 268.

Gibbons, R. A. (1963). Biochem. J. 89, 380.

Gibbons, R. A. \& Roberts, G. P. (1963). Ann. N.Y. Acad. Sci. 106, 218.
Glass, G. B. J. (1965). In Gastric Secretion: Mechanism and Control, p. 187. Ed. by Shnitka, T. K., Gilbert, J. A. L. \& Harrison, R. C. Oxford: Pergamon Press Ltd.

Glass, G. B. J., Rich, M. \& Stephenson, L. (1964). Clinica chim. Acta, 9, 509.

Gottschalk, A. (1966). Glycoproteins, p. 1. Amsterdam: Elsevier Publishing Co.

Ito, S. (1965). In Gastric Secretion: Mechanism and Control, p. 3. Ed. by Shnitka, T. K., Gilbert, J. A. L. \& Harrison, R. C. Oxford: Pergamon Press Ltd.

Kabat, E. A. (1956). Blood Group Substances, p. 135. New York: Academic Press Inc.

Kabat, E. A. \& Bezer, A. E. (1945). J. exp. Med. 82, 207.

Kent, P. W. \& Marsden, J. C. (1963). Biochem. J. 87, 38P.

Kohn, J. \& Feinberg, J. G. (1965). Shandon Instrument Applications no. 11 : Electrophoresis in Cellulose Acetate.

Kristiansen, T. \& Porath, J. (1968). Biochim. biophys. Acta, 158, 351.

Ludoweig, J. \& Benmaman, J. D. (1967). Analyt. Biochem. 19, 80.

Mahowald, T. A., Noltmann, E. A. \& Kuby, S. A. (1962). J. biol. Chem. 237, 1138.

Marcussen, J. M. (1970). In The Physiology of Gastric Secretion, p. 440. Ed. by Semb, L. S. \& Myren, J. Oslo: Universitets Forlaget.

Meyer, K., Smyth, E. M. \& Palmer, J. W. (1937). J. biol. Chem. 119, 73.

Morgan, W. T. J. \& King, H. K. (1943). Biochem. J. 37, 640.

Pamer, T., Glass, G. B. J. \& Horowitz, M. I. (1968). Biochemistry, Easton, 7, 3821.

Pusztai, A. \& Morgan, W. T. J. (1963). Biochem. J. 88, 546.

Seifter, S., Dayton, S., Novic, B. \& Muntwyler, E. (1950). Archs Biochem. Biophys. 25, 191.

Skoryna, S. C. \& Waldron-Edwards, D. (1967). Ann. N.Y. Acad. Sci. 140, 835.

Smith, I. (1960). Chromatographic and Electrophoretic Techniques, vol. 2, p. 56. London: W. Heinemann Ltd.

Snary, D. (1970). Ph.D. Thesis: University of Newcastle upon Tyne.

Snary, D. \& Allen, A. (1969). Biochem. J. 114, 85P.

Snary, D. \& Allen, A. (1971). Biochem. J. (in the Press).

Snary, D., Allen, A. \& Pain, R. H. (1970). Biochem. biophys. Res. Commun. 40, 844.

Szulman, A. E. (1960). J. exp. Med. 111, 785.

Watkins, W. M. (1966). In Glycoproteins, p. 462. Ed. by Gottschalk, A. Amsterdam: Elsevier Publishing Co.

Weimer, H. E. \& Moshin, J. R. (1953). Am. Rev. Tuberc. pulm. Dis. 68, 594. 